\title{
Effects of dietary cis and trans unsaturated and saturated fatty acids on the glucose metabolites and enzymes of rats
}

\author{
Claudio A. Bernal ${ }^{1,2} *$, Jordi Rovira ${ }^{3}$, María E. Colandré ${ }^{1}$, Roser Cussó ${ }^{3}$ and Joan A. Cadefau ${ }^{3}$ \\ ${ }^{1}$ Cátedra Bromatología y Nutrición, Facultad de Bioquímica y Ciencias Biológicas, Universidad Nacional del Litoral, \\ Santa Fe, Argentina \\ ${ }^{2}$ Consejo Nacional de Investigaciones Científicas y Técnicas (CONICET), Santa Fe, Argentina \\ ${ }^{3}$ Departamento de Ciencias Fisiológicas I, Facultad de Medicina, Universidad de Barcelona, Instituto de Investigaciones \\ Biomédicas August Pi i Sunyer (IDIBAPS), Barcelona, Spain
}

(Received 20 July 2005 - Revised 12 January 2006 - Accepted 24 January 2006)

\begin{abstract}
The aim of the present study was to examine whether the level of dietary cis fatty acid (cFA), or the isomers (trans or cis) and/or the saturation of the fatty acids at high dietary fat levels altered the intracellular glucose metabolites and certain regulatory enzyme activities in the skeletal muscle and liver of rats. The animals were fed for $30 \mathrm{~d}$ on either a recommended control diet ( $7 \% c$ FA, w/w) or a high-fat diet ( $20 \%$ fatty acids, w/w). The high-fat diet was enriched with either $c$ FA, trans fatty acid $(t \mathrm{FA})$, a moderate proportion of saturated fatty acid (MSFA), or a high proportion of saturated fatty acid (HSFA). The most striking findings were observed in the gastrocnemius muscle with a HSFA diet. There was a significant increase in glucose-6-phosphate (306\%), glucose-1-phosphate (245\%), fructose-6-phosphate (400\%), fructose-1,6-bisphosphate (86\%), glyceraldehyde-3-phosphate $(38 \%)$, pyruvate $(341 \%)$, lactate $(325 \%)$, citrate $(79 \%)$ and the bisphosphorylated sugars as compared with the $c$ FA diet. These changes were paralleled by an increase in muscle triacylglycerol content $(49 \%)$ and a decrease in glucose (39\%). In addition, the amount of $c \mathrm{FA}$ and the other types of fatty acid (i.e. $t \mathrm{FA}$ and MSFA) led to no great differences in glucose metabolism as compared with the respective control group. These data support the hypothesis that glucose changes induced by a HSFA diet are a multifaceted abnormality. Glucose and lactate transport and intracellular glucose metabolism could be the key biochemical defects involved in this detrimental effect on glucose metabolism
\end{abstract}

Trans fatty acids: Saturated fatty acids: Dietary fat: Glucose metabolism

Many epidemiological and experimental studies (Lichtenstein et al. 1998; Grundy et al. 2002; Riccardi et al. 2004) suggest that the amount and type of fats consumed influence the development and subsequent progression of several major diseases, including CHD, obesity, diabetes and cancer. It is widely known that a high intake of saturated fatty acids (SFA) (Storlien et al. 1991; Alsaif \& Duwaihy, 2004) and trans fatty acids ( $t$ FA) (Clevidence et al. 1997; Ascherio et al. 1999) has an adverse impact on the plasma lipid profile, and increases the risk of developing CVD and type 2 diabetes.

The effect of diets high in fatty acids on glucose metabolism in human subjects and in experimental animal models is well documented in the literature. For example, Uusitupa et al. (1994) reported that in normal female subjects a highfat diet (total fat energy $40 \%$ ) reduces the glucose tolerance; similarly, in their thorough review Lichtenstein \& Schwab (2000) showed that impaired glucose tolerance and insulin resistance are induced by high-fat feeding in experimental animals. Such effects are also influenced by the dietary fatty acid composition. Animals fed on high-SFA diets develop glucose intolerance (Wang et al. 2002) and impairment of insulin action in both skeletal muscle and liver (Storlien et al. 1991; Oakes et al. 1997). Kim et al. (1996) reported that when rats are fed a high-saturated fat diet, glycolysis is suppressed and glycogen synthesis is altered in skeletal muscle. They hypothesised that these changes might lead to the development of insulin resistance. However, whereas $n$-3 PUFA improve insulin action, $n-6$ PUFA have a slight negative impact on insulin sensitivity (Storlien et al. 1991; Mohan \& Das, 2001; Taouis et al. 2002).

Several studies (Judd et al. 1994; Zock \& Katan, 1997) have shown that $t \mathrm{FA}$ increase both total and LDL-cholesterol levels, resembling some of the dietary high proportion of SFA (HSFA) effects. Although a number of conflicting results have been described, some studies indicate that $t \mathrm{FA}$ decreases HDL-cholesterol (Judd et al. 1994) and increases plasma lipoprotein (a) levels (Aro et al. 1997). The specific effect of dietary $t$ FA on the glucose metabolic pathway, as compared with

Abbreviations: $c$ FA, cis unsaturated fatty acid; F-1,6- $\mathrm{P}_{2}$, fructose-1,6-bisphosphate; F-2,6- $\mathrm{P}_{2}$, fructose-2,6-bisphosphate; F-6-P, fructose-6-phosphate; G-1-P, glucose-1-phosphate; G-1,6- $\mathrm{P}_{2}$, glucose-1,6-bisphosphate; G-6-P, glucose-6-phosphate; HSFA, high saturated fatty acid; MSFA, moderate saturated fatty acid; PFK-1, 6-phosphofructo-1-kinase; SFA, saturated fatty acid; $t$ FA, trans unsaturated fatty acid.

* Corresponding author: Professor Claudio Bernal, fax +54 342 4575221, email cbernal@fbcb.unl.edu.ar 
SFA and/or cis fatty acid ( $c$ FA) at high fat levels, has not been determined. Dietary $t$ FA might exert different effects on the glucose oxidation pathway, as they do on lipid metabolism. In this regard, Louheranta et al. (1999) showed that a $t \mathrm{FA}$ diet has no effect on glucose and insulin metabolism as compared with a MUFA diet in young healthy women. Alternatively, Alstrup et al. (1999) demonstrated that in mouse $\beta$ cells $t$ FA potentiates glucose-stimulated insulin secretion more than $c$ FA of the same carbon-chain length. This is probably due to a differential effect on glucose oxidation. Cromer et al. (1995) demonstrated that $t$ FA might inhibit glucose oxidation in adipocytes isolated from rats.

Therefore, high levels of dietary fatty acid might alter glucose tolerance. This effect appears to be dependent on the type of fatty acid. We can also assume that a suppression of intracellular glucose metabolism by competition for substrate oxidation might precede and/or cause insulin resistance in skeletal muscle. On the basis of these assumptions, we aimed to evaluate the glucose metabolites and some key enzyme activities involved in skeletal muscle and liver glucose metabolism on an experimental animal model. The variables were: (1) the amount of dietary $c \mathrm{FA}$; (2) the isomers (trans or cis) and/or the degree of saturation (high or moderate) of dietary fat.

\section{Materials and methods}

\section{Materials}

Nutrients for diet preparations were chemical grade, with the exception of maize oil (Mazola, Argentina), sucrose, cellulose, and maize starch, which were commercial grade obtained from a local source. The same maize oil was used to prepare both isomerised and saturated fats, as previously described (Colandré et al. 2003). Biochemical reagents, enzymes and standards were purchased from Sigma Chemical Co. (St Louis, MO, USA) or Roche Molecular Biochemicals (Barcelona, Spain). Plasma glucose kits were purchased from Wiener Co. (Rosario, Argentina). Catalytic palladium in charcoal was from Alpha Aesar Co. (Ward Hill, MA, USA). Solvents and reagents used for quantifying fatty acids were chromatography grade. All the other chemicals used were of the highest analytical grade.

\section{Animals, diets and tissue preparation}

All the animal studies were conducted in accordance with the principles of our School of Biochemistry regulations, compiled using the Guide to the Care and Use of Experimental Animals of the Laboratory (Institute of Laboratory Animal Resources et al. 1996). Male Wistar rats weighing 80-100 g were supplied by the Comisión Nacional de Energía Atómica (Buenos Aires, Argentina). They were housed in animal quarters under controlled conditions $\left(23 \pm 2^{\circ} \mathrm{C}\right.$ and $12 \mathrm{~h}$ lightdark cycle) in individual cages. The animals had free access to water and a standard diet until reaching a weight of $120-130 \mathrm{~g}$. After this, they were randomly divided into five weight-matched groups and fed each diet ad libitum for $30 \mathrm{~d}$.

All diets were nutritionally adequate and differed either in the amount of $c \mathrm{FA}$, or in the fatty acid composition (Table 1). The control diet was based on the American Institute of Nutrition Ad Hoc Committee recommendation (AIN-93G diet formulated for the growth, pregnancy and lactation phases of rodents; Reeves et al. 1993). It contained $70 \mathrm{~g}$ fat $/ \mathrm{kg}$. All other diets were enriched by replacing carbohydrate with fat, to attain $200 \mathrm{~g} / \mathrm{kg}(38.5 \%$ energy as fat). These enriched fat diets contained $30 \mathrm{~g}$ maize oil/ $/ \mathrm{kg}$ to exceed the essential fatty acid recommendations, and fats with different compositions $(170 \mathrm{~g} / \mathrm{kg})$. The $c$ FA diet was enriched with $170 \mathrm{~g} c \mathrm{FA} / \mathrm{kg}$ (from maize oil). The $t \mathrm{FA}$ diet was enriched with isomerised maize oil $(170 \mathrm{~g} / \mathrm{kg})$ containing $300 \mathrm{~g} t \mathrm{FA} / \mathrm{kg}$. The moderate proportion of SFA (MSFA) diet was enriched with MSFA based on a blend of maize oil $(119 \mathrm{~g} / \mathrm{kg})$ and hydrogenated maize oil $(59 \mathrm{~g} / \mathrm{kg})$, and the HSFA diet was enriched with SFA from hydrogenated maize oil $(170 \mathrm{~g} / \mathrm{kg})$.

The preparation of the experimental dietary fats and the methodology for evaluating their fatty acid composition was recently described (Colandré et al. 2003). The fatty acid composition of the experimental fats used is shown in Table 2. Each diet was freshly prepared every $3 \mathrm{~d}$ during the experimental period.

Body weight and food consumption were measured throughout the experimental period. After $30 \mathrm{~d}$ of dietary treatment, rats were anaesthetised with acepromazine $(1 \mathrm{mg} / \mathrm{kg}$ body weight) and ketamine $(100 \mathrm{mg} / \mathrm{kg}$ body weight) and blood was collected in heparinised tubes. After blood

Table 1. Composition of the experimental diets*

\begin{tabular}{|c|c|c|c|c|c|}
\hline Ingredient & Control diet & $c$ FA diet & $t \mathrm{FA}$ diet & MSFA diet & HSFA diet \\
\hline Maize starch (g/kg diet) & $529 \cdot 5$ & $399 \cdot 5$ & $399 \cdot 5$ & $399 \cdot 5$ & $399 \cdot 5$ \\
\hline Casein (g/kg diet) & 200 & 200 & 200 & 200 & 200 \\
\hline Sucrose ( $\mathrm{g} / \mathrm{kg}$ diet) & 100 & 100 & 100 & 100 & 100 \\
\hline Maize oil (g/kg diet) & 70 & 200 & 30 & 149 & 30 \\
\hline Isomerised maize oil (g/kg diet) & - & - & 170 & - & - \\
\hline Hydrogenated maize oil (g/kg diet) & - & - & - & 51 & 170 \\
\hline Fibre ( $\mathrm{g} / \mathrm{kg}$ diet) & 50 & 50 & 50 & 50 & 50 \\
\hline Mineral mixture ( $\mathrm{g} / \mathrm{kg}$ diet) & 35 & 35 & 35 & 35 & 35 \\
\hline Vitamin mixture ( $\mathrm{g} / \mathrm{kg}$ diet) & 10 & 10 & 10 & 10 & 10 \\
\hline L-Cystine-L-methionine (g/kg diet) & 3.0 & 3.0 & $3 \cdot 0$ & 3.0 & 3.0 \\
\hline Choline ( $\mathrm{g} / \mathrm{kg}$ diet) & 2.5 & 2.5 & 2.5 & 2.5 & $2 \cdot 5$ \\
\hline Energy $(\mathrm{kJ} / 100 \mathrm{~g})$ & $1656 \cdot 9$ & $1928 \cdot 8$ & $1928 \cdot 8$ & $1928 \cdot 8$ & $1928 \cdot 8$ \\
\hline
\end{tabular}

$c F A$, cis fatty acid; $t F A$, trans fatty acid; MSFA, moderate level of saturated fatty acid; HSFA, high level of saturated fatty acid. *Vitamin and mineral mixtures were prepared according to Reeves et al. (1993). 
Table 2. Fatty acid composition of experimental fats (Mean values)

\begin{tabular}{|c|c|c|c|}
\hline \multirow[b]{2}{*}{ Fatty acids } & \multicolumn{3}{|c|}{$\begin{array}{l}\text { Experimental maize oil (weight percentage } \\
(\mathrm{w} / \mathrm{w}) \text { of the total fatty acid methyl esters) }\end{array}$} \\
\hline & Non-treated & Isomerised & Hydrogenated \\
\hline $16: 0$ & $10 \cdot 78$ & $10 \cdot 87$ & $11 \cdot 23$ \\
\hline$c 16: 1$ & $0 \cdot 20$ & $0 \cdot 10$ & $0 \cdot 15$ \\
\hline $18: 0$ & $2 \cdot 24$ & $2 \cdot 61$ & $59 \cdot 33$ \\
\hline$t 18: 1$ & ND & $26 \cdot 47$ & $10 \cdot 47$ \\
\hline$c 18: 1$ & $31 \cdot 36$ & $25 \cdot 41$ & $17 \cdot 22$ \\
\hline$t, t 18: 2$ & ND & 2.09 & ND \\
\hline$t, c 18: 2+c, t 18: 2$ & 0.48 & $1 \cdot 35$ & ND \\
\hline$c, c 18: 2$ & $52 \cdot 85$ & $29 \cdot 57$ & 0.50 \\
\hline$t, c, c 18: 3$ & 0.06 & 0.03 & ND \\
\hline$c, c, c 18: 3$ & 0.75 & 0.41 & ND \\
\hline $20: 0$ & 0.52 & 0.52 & 0.68 \\
\hline$t 20: 1$ & 0.12 & 0.07 & ND \\
\hline$c 20: 1$ & 0.24 & 0.13 & 0.22 \\
\hline $22: 0$ & 0.20 & 0.18 & 0.12 \\
\hline $24: 0$ & 0.20 & 0.19 & 0.08 \\
\hline$\%$ Trans fatty acids & 0.66 & $30 \cdot 00$ & $10 \cdot 47$ \\
\hline$\%$ Saturated fatty acids & 13.94 & $14 \cdot 38$ & 71.44 \\
\hline
\end{tabular}

$c$, cis; $t$, trans; ND, not detected.

collection, samples of gastrocnemius muscle and liver were taken. Plasma was separated by centrifugation at $3000 \mathrm{~g}$ for $10 \mathrm{~min}$. Sample tissues were immediately frozen at $-80^{\circ} \mathrm{C}$ and stored until analysis. For glycolytic metabolites and enzyme analysis, a portion of each sample was lyophilised and stored under dry conditions at $-20^{\circ} \mathrm{C}$.

\section{Analysis of muscle and liver glycogen concentrations}

Glycogen was extracted from about $4-5 \mathrm{mg}$ dry tissue by acid treatment at $100^{\circ} \mathrm{C}$ (Adamo \& Graham, 1998). The glucose produced was measured using the enzymic method with fluorimetric techniques (Lowry \& Passonneau, 1972).

\section{Analysis of metabolite concentrations}

Plasma glucose levels were determined using commercial kits (Wiener, Rosario, Argentina).

ATP, creatine, phosphate creatine, glucose, glucose-6phosphate (G-6-P), glucose-1-phosphate (G-1-P), fructose-6phosphate (F-6-P), fructose-1,6-bisphosphate (F-1,6- $\left.\mathrm{P}_{2}\right)$, dihydroxyacetone-phosphate, glyceraldehyde-3-phosphate, lactate, pyruvate and citrate were extracted by acid treatment from $3-5 \mathrm{mg}$ dry muscle and liver tissue in ice-cold $0.5 \mathrm{M}$-perchloric acid. After centrifugation and neutralisation, samples of the extracts were used. Measurements were carried out using enzymatic methods with fluorimetric techniques (Lowry \& Passonneau, 1972).

About 5-10 mg dry tissue powder was homogenised in 5 volumes of $50 \mathrm{~mm}-\mathrm{NaOH}$ and kept at $90^{\circ} \mathrm{C}$ for $10 \mathrm{~min}$. The extracts were neutralised with ice-cold acetic acid and the soluble materials were used to measure fructose-2,6-bisphosphate $\left(\mathrm{F}-2,6-\mathrm{P}_{2}\right)$ (van Schaftingen et al. 1982) and glucose-1,6bisphosphate (G-1,6- $\left.\mathrm{P}_{2}\right)$ (Passonneau et al. 1969). To minimise the effect of blood and connective tissue on the freeze-dried tissue, the total creatine content (sum of phosphate creatine and creatine) for a given individual sample was determined. It was then used to adjust individual metabolite concentrations (Sabina et al. 1984).

\section{Determination of liver and muscle triacylglycerol content}

Fresh liver and muscle tissue samples were homogenised in 10 volumes of saline solution and used to measure triacylglycerol, by the method of Laurell (1966).

\section{Analysis of enzyme activities}

Powdered muscle and liver were homogenised in 70 volumes (w/v) of ice-cold extraction buffer (containing $50 \mathrm{~mm}$-tri(hydroxymethyl)-aminomethane- $\mathrm{HCl}, 4 \mathrm{~mm}-\mathrm{EDTA}, 30 \mathrm{~mm}-\mathrm{KF}$, $30 \mathrm{~mm}-\beta$-mercaptoethanol; $\mathrm{pH} 7 \cdot 0$ ). The homogenate was centrifuged at $12000 \mathrm{~g}$ for $15 \mathrm{~min}$ at $4^{\circ} \mathrm{C}$ and the supernatant fraction was used to measure the activities of 6-phosphofructo-1-kinase (PFK-1) (Cadefau et al. 1990). Citrate synthase activity in liver and muscle was assessed according to Bass et al. (1969).

\section{Statistics}

We used the unpaired Student's $t$ test to determine the statistical differences between dietary levels of cis unsaturated fats (control diet $v$. $c$ FA diet). Comparisons of fatty acid composition at high level of dietary fats $(200 \mathrm{~g} / \mathrm{kg})$ were established by one-way ANOVA $(1 \times 4)$. When ANOVA showed significant differences between dietary groups, the Tukey test was performed. All differences were considered significant at $P<0 \cdot 05$. Values are expressed as means with their standard errors of five or six animals per group.

\section{Results}

No differences could be observed between the diets in either average daily food energy intake (control diet 273.6 (SE $13.1) \mathrm{kJ} / \mathrm{d}, c$ FA diet $265.0(\mathrm{SE} 6.8) \mathrm{kJ} / \mathrm{d}, t \mathrm{FA}$ diet 247.7 (SE 4.2) $\mathrm{kJ} / \mathrm{d}$, MSFA diet 254.9 (SE 11.5) kJ/d, HSFA diet 270.7 (SE 21.2$) \mathrm{kJ} / \mathrm{d} ; P>0.05$ ) or body-weight gain (control diet 133.9 (SE 6.6) g/30 d, $c$ FA diet 139.2 (SE 4.1) g/30 d, $t \mathrm{FA}$ diet 136.3 (SE 4.3) g/30 d, MSFA diet 133.6 (SE 6.5) g/30 d, HSFA diet 138.7 (SE 4.3) g/30d; $P>0.05$ ). No differences could be found between the groups in the levels of metabolites related to the energetic content of the tissues, specifically ATP in muscle and liver and total creatine in muscle (Table 3). These metabolites also reflected storage conditions and manipulation of the samples.

When levels of $c$ FA were considered, no differences were found in plasma glucose concentrations under fasted conditions, or in muscle and liver triacylglycerol content (Table 3). However, the type of fatty acid in the high-fat diets affected plasma glucose concentrations and muscle triacylglycerol content. These were both higher in the HSFA diet $(P<0.05$ v. $c \mathrm{FA})$. Liver triacylglycerol content was higher in $t$ FA, MSFA and HSFA diets $(P<0.05 v . c$ FA $)$.

Compared with the recommended levels of fat, high levels of $c$ FA significantly decreased pyruvate concentration and increased F-6-P, G-1,6- $\mathrm{P}_{2}$ and F-2,6- $\mathrm{P}_{2}$ in muscle (Table 4). No differences were observed in all the other metabolites 
Table 3. Plasma glucose and triacylglycerol (TG), and ATP and creatine content in muscle and liver†

(Mean values with their standard errors of five or six animals per group)

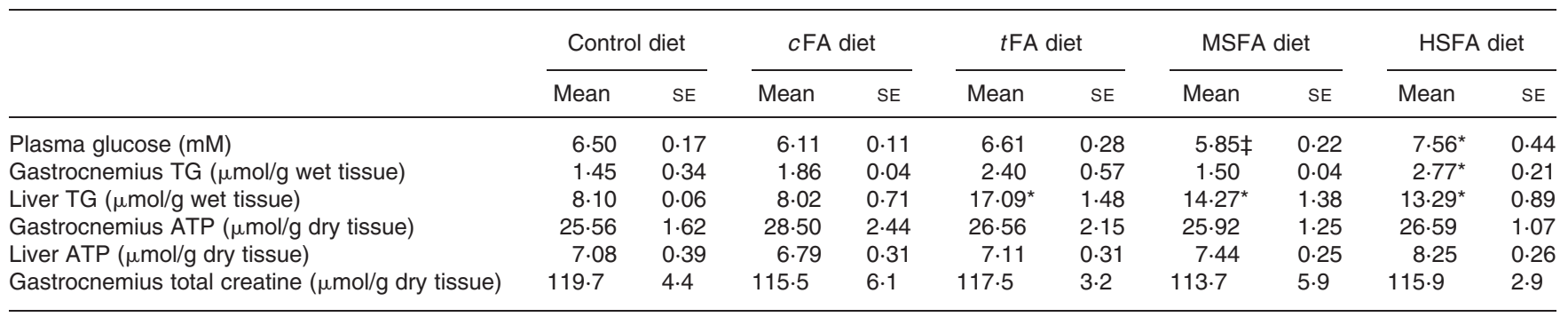

$c F A$, cis unsaturated fatty acid; $t$ FA, trans unsaturated fatty acid; MSFA, moderate saturated fatty acid; HSFA, high saturated fatty acid.

${ }^{*}$ Mean value was significantly different from that for the $c$ FA diet $(P<0.05)$.

†The comparison of cis fatty acid levels was not significantly different, by unpaired Student's $t$ test, at $P<0.05$. Comparison of fatty acid composition at high dietary fat levels was established by ANOVA $(1 \times 4)$ followed by the Tukey test. For details, see p. 949. $\ddagger n 3$.

analysed in muscle or liver. In addition, no changes in muscle PFK-1 and citrate synthase or in hepatic PFK-1 and citrate synthase activities were observed after $30 \mathrm{~d}$ of the high$c$ FA-level diet.

The effects of different compositions of fatty acids at high fat levels on muscle and liver metabolites are shown in Fig. 1, Fig. 2, Fig. 3 and Fig. 4. Thus, Fig. 1 shows a significant reduction in glucose levels and a significant increase of G-6$\mathrm{P}, \mathrm{F}-6-\mathrm{P}$ and $\mathrm{F}-1,6-\mathrm{P}_{2}$ in the gastrocnemius muscle of rats fed a HSFA diet as compared with a $c$ FA diet. In addition, muscle G-6-P and F-6-P were increased in HSFA $v$. tFA and $v$. MSFA diets; and muscle F-6-P in the HSFA diet $v$. the MSFA diet. No differences were observed in muscle and liver glucose, G-6-P, F-6-P and F-1,6- $\mathrm{P}_{2}$ between the $c$ FA, tFA and MSFA diets. In gastrocnemius muscle, the HSFA diet significantly increased the G-1-P levels as compared with any other type of high-fat-level diet. The glycogen level was slightly reduced by the HSFA diet, reaching statistical significance only between the HSFA diet and the MSFA diet (Fig. 2) in muscle. No differences were detected in hepatic G-1-P and glycogen content between the high-dietary fat groups. The HSFA diet increased the muscle pyruvate, lactate and citrate levels $v$. $c$ FA, tFA or MSFA diets. The $t$ FA diet increased the muscle pyruvate levels $v$. the $c$ FA diet. Surprisingly, the HSFA diet also significantly increased the citrate levels in liver, with no changes in the other metabolites analysed (Fig. 3). G-1,6- $\mathrm{P}_{2}$ and F-2,6- $\mathrm{P}_{2}$ were not changed by any type of fatty acid at high levels of fat intake either in muscle or liver. However, in muscle both bisphosphorylated sugars were significantly higher in HSFA diets with regard to the control diet (Fig. 4).

Fig. 5 shows regulatory enzyme activities in the muscle and liver of rats fed high fat levels with different compositions of fatty acid. No differences in PFK-1 and citrate synthase

Table 4. Effect of cis unsaturated fat level on glycolytic metabolites contents and enzyme activities in the muscle and liver (Mean values with their standard errors of five or six animals)

\begin{tabular}{|c|c|c|c|c|c|c|c|c|}
\hline & \multicolumn{4}{|c|}{ Muscle } & \multicolumn{4}{|c|}{ Liver } \\
\hline & \multicolumn{2}{|c|}{ Control diet† } & \multicolumn{2}{|c|}{$c$ FA diet $\ddagger$} & \multicolumn{2}{|c|}{ Control diet† } & \multicolumn{2}{|c|}{$c$ FA diet $\ddagger$} \\
\hline & Mean & SE & Mean & SE & Mean & SE & Mean & SE \\
\hline Glycogen content ( $\mu \mathrm{mol}$ glucose/g dry tissue) & $125 \cdot 9$ & $3 \cdot 3$ & $131 \cdot 7$ & $4 \cdot 5$ & $887 \cdot 1$ & $76 \cdot 0$ & $793 \cdot 2$ & $46 \cdot 8$ \\
\hline Glucose content ( $\mu \mathrm{mol} / \mathrm{g}$ dry tissue) & $2 \cdot 91$ & 0.36 & $2 \cdot 88$ & 0.32 & $26 \cdot 3$ & 1.4 & $25 \cdot 4$ & $2 \cdot 2$ \\
\hline G-1-P content ( $\mu \mathrm{mol} / \mathrm{g}$ dry tissue) & 0.14 & 0.02 & $0 \cdot 11$ & 0.02 & 0.17 & 0.02 & 0.18 & 0.02 \\
\hline G-6-P content ( $\mu \mathrm{mol} / \mathrm{g}$ dry tissue) & $0 \cdot 71$ & $0 \cdot 16$ & $1 \cdot 12$ & $0 \cdot 13$ & 1.39 & $0 \cdot 16$ & 1.02 & 0.08 \\
\hline F-6-P content ( $\mu \mathrm{mol} / \mathrm{g}$ dry tissue) & 0.14 & 0.01 & $0 \cdot 20^{*}$ & 0.02 & 0.38 & 0.04 & 0.26 & 0.02 \\
\hline $\mathrm{F}-1,6-\mathrm{P}_{2}$ content $(\mu \mathrm{mol} / \mathrm{g}$ dry tissue) & $3 \cdot 71$ & 0.66 & $2 \cdot 75$ & 0.35 & 0.18 & 0.01 & 0.23 & 0.02 \\
\hline DHAP content $(\mu \mathrm{mol} / \mathrm{g}$ dry tissue $)$ & 0.28 & 0.05 & 0.21 & 0.07 & 0.08 & 0.01 & 0.09 & 0.03 \\
\hline Gly-3-P content ( $\mu \mathrm{mol} / \mathrm{g}$ dry tissue) & 0.04 & 0.01 & 0.03 & 0.01 & 0.05 & 0.01 & 0.06 & 0.01 \\
\hline Lactate content ( $\mu \mathrm{mol} / \mathrm{g}$ dry tissue) & $6 \cdot 27$ & 0.59 & 4.98 & 0.40 & $19 \cdot 4$ & 1.50 & $18 \cdot 6$ & $1 \cdot 8$ \\
\hline Pyruvate content ( $\mu \mathrm{mol} / \mathrm{g}$ dry tissue) & 0.34 & 0.03 & $0 \cdot 22^{*}$ & 0.03 & 0.35 & 0.07 & 0.26 & 0.01 \\
\hline Citrate content $(\mu \mathrm{mol} / \mathrm{g}$ dry tissue) & 0.43 & 0.04 & 0.53 & 0.06 & 0.55 & 0.09 & 0.50 & 0.09 \\
\hline $\mathrm{F}-2,6-\mathrm{P}_{2}$ content (nmol/g dry tissue) & $4 \cdot 27$ & $0 \cdot 27$ & $6 \cdot 57^{*}$ & 0.68 & $25 \cdot 0$ & $2 \cdot 5$ & $26 \cdot 0$ & 3.0 \\
\hline G-1,6- $\mathrm{P}_{2}$ content (nmol/g dry tissue) & 233.4 & 41.3 & $455 \cdot 7^{*}$ & $46 \cdot 3$ & $185 \cdot 0$ & $26 \cdot 3$ & $203 \cdot 6$ & $23 \cdot 3$ \\
\hline PFK-1 activity (U/g dry tissue) & $196 \cdot 9$ & $10 \cdot 3$ & $196 \cdot 2$ & $19 \cdot 7$ & $3 \cdot 19$ & 0.23 & $3 \cdot 14$ & 0.17 \\
\hline Citrate synthase activity (U/g dry tissue) & $62 \cdot 6$ & $6 \cdot 8$ & 64.5 & $6 \cdot 3$ & $18 \cdot 1$ & 0.9 & $17 \cdot 9$ & 1.8 \\
\hline
\end{tabular}

cFA, cis unsaturated fatty acid; G-1-P, glucose-1-phosphate; G-6-P, glucose-6-phosphate; F-6-P, fructose-6-phosphate; F-1,6- $\mathrm{P}_{2}$, fructose-1,6-bisphosphate;

DHAP, dihydroxyacetone-phosphate; Gly-3-P, glyceraldehyde-3-phosphate; F-2,6- $P_{2}$, fructose-2,6-bisphosphate; G-1,6- $\mathrm{P}_{2}$, glucose-1,6-bisphosphate; PFK-1, 6-phosphofructo-1-kinase.

* Mean value was significantly different from that for the control diet $(P<0.05)$. For details, see p. 949.

† Dietary fat $70 \mathrm{~g} / \mathrm{kg}$

$\ddagger$ Dietary fat $200 \mathrm{~g} / \mathrm{kg}$. 

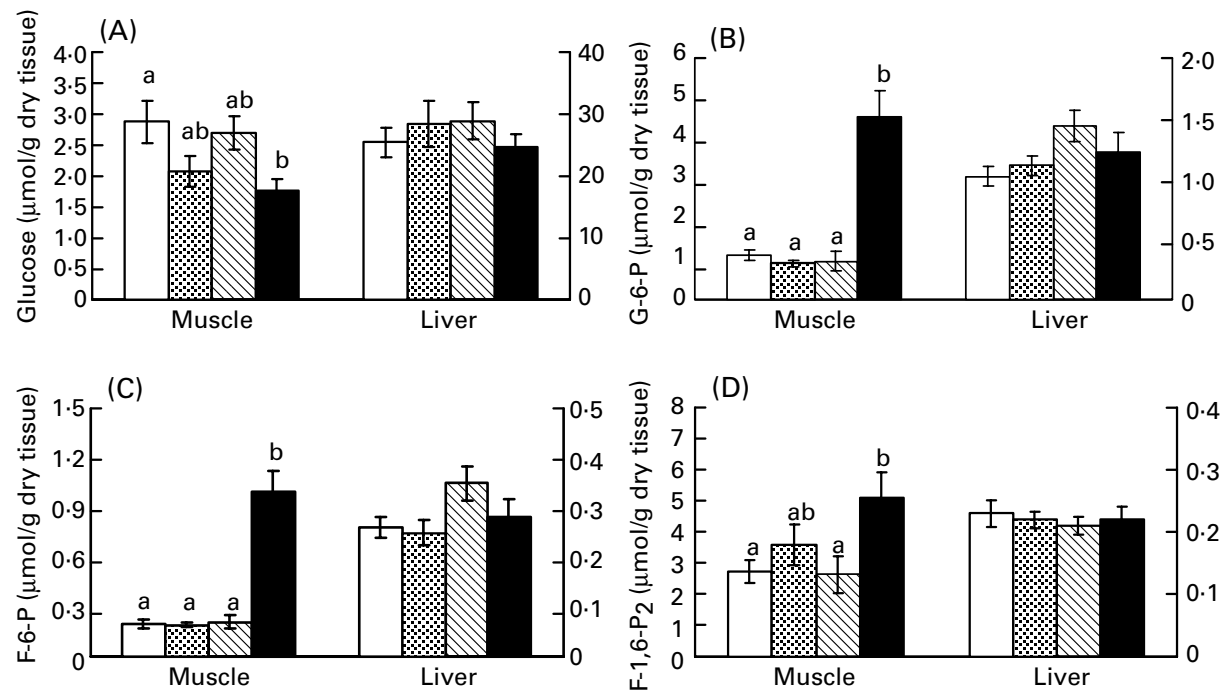

Fig. 1. Glucose (A), glucose-6-phosphate (G-6-P) (B), fructose-6-phosphate (F-6-P) (C) and fructose-1,6-bisphosphate (F-1,6-P $)(D)$ content in the muscle and liver of animals fed high levels of fat. Values are means of five to six animals, with their standard errors represented by vertical bars. ( $\square$ ), Cis unsaturated fatty

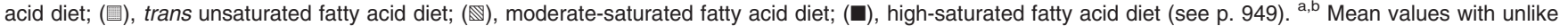
letters were significantly different $(P<0.05)$ by Tukey's test, after significant differences were found by one-way ANOVA $(1 \times 4)$.

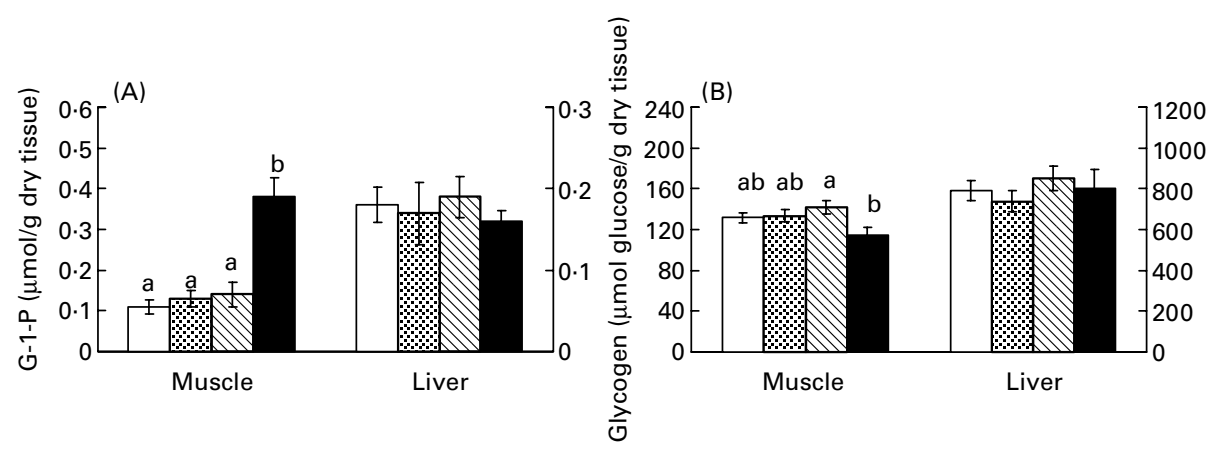

Fig. 2. Glucose-1-phosphate (G-1-P) (A) and glycogen (B) content in the muscle and liver of animals fed high levels of fat. Values are means of five to six animals,

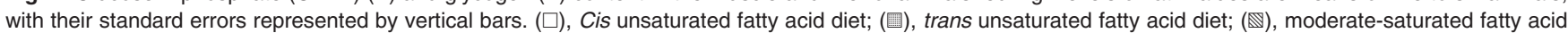
diet; ( $\square)$, high-saturated fatty acid diet (see p. 949). ${ }^{\text {a,b }}$ Mean values with unlike letters were significantly different $(P<0.05)$ by Tukey's test, after significant differences were found by one-way ANOVA $(1 \times 4)$.

activities in muscle and liver were observed between the dietary groups. However, the muscle F-1,6- $\mathrm{P}_{2}: \mathrm{F}-6-\mathrm{P}$ ratio, used as an index of flux through PFK-1, was significantly reduced by the HSFA diet, mainly with regard to the control diet. The mean values of the $\mathrm{F}-1,6-\mathrm{P}_{2}: \mathrm{F}-6-\mathrm{P}$ ratio in gastrocnemius muscle were: control diet, $26 \cdot 5$ (SE $1 \cdot 21) ; c$ FA diet, $13 \cdot 37$ (SE 0.64) $\quad(P<0.05 \quad v$. control diet); $t$ FA diet, 18.31 (SE 2.37); MSFA diet, 12.69 (SE 0.90) $(P<0.05 v$. control diet); HSFA diet, 5.80 (SE 1.09) $(P<0.05 v$. control diet).

\section{Discussion}

Dietary fats have been shown to lead to insulin resistance (Storlien et al. 1997) and glucose metabolism changes. It is widely recognised that both the amount and type of dietary fatty acids modify insulin sensitivity in the muscle and liver of experimental animals (Storlien et al. 1986). In addition, intracellular glucose metabolism suppression might precede and/or cause insulin resistance in the skeletal muscle of rats fed a high-fat diet (Kim et al. 2000). In view of these assumptions, we evaluated the glucose metabolites and key enzyme activities in skeletal muscle and liver on an experimental dietary model. The variables were: (1) the amount of dietary $c \mathrm{FA}$; (2) the isomers (trans or cis) and/or the saturation of fatty acid at high dietary fat levels.

The levels of dietary $c$ FA did not change the muscle and liver triacylglycerol content under our experimental conditions. In addition, dietary $c$ FA levels did not lead to pronounced changes in glucose metabolism. The most remarkable changes at high levels of $c \mathrm{FA}$ are the increases in F-6-P, F-2,6- $\mathrm{P}_{2}$ and $\mathrm{G}-1,6-\mathrm{P}_{2}$ in muscle. High levels of the allosteric activators of PFK-1 (F-2,6- $\mathrm{P}_{2}$ and G-1,6- $\left.\mathrm{P}_{2}\right)$ could maintain the glycolytic pathway, increasing muscle glucose utilisation. On the other hand, citrate, an allosteric inhibitor of PFK-1, is not influenced by dietary levels of $c$ FA.

Our most striking finding is that the type of dietary fatty acid, rather than the level of fat content per se, may be a decisive factor in the detrimental effects of dietary fat on muscle glucose metabolites. Animals fed the HSFA diet showed significantly increased muscle triacylglycerol content associated 

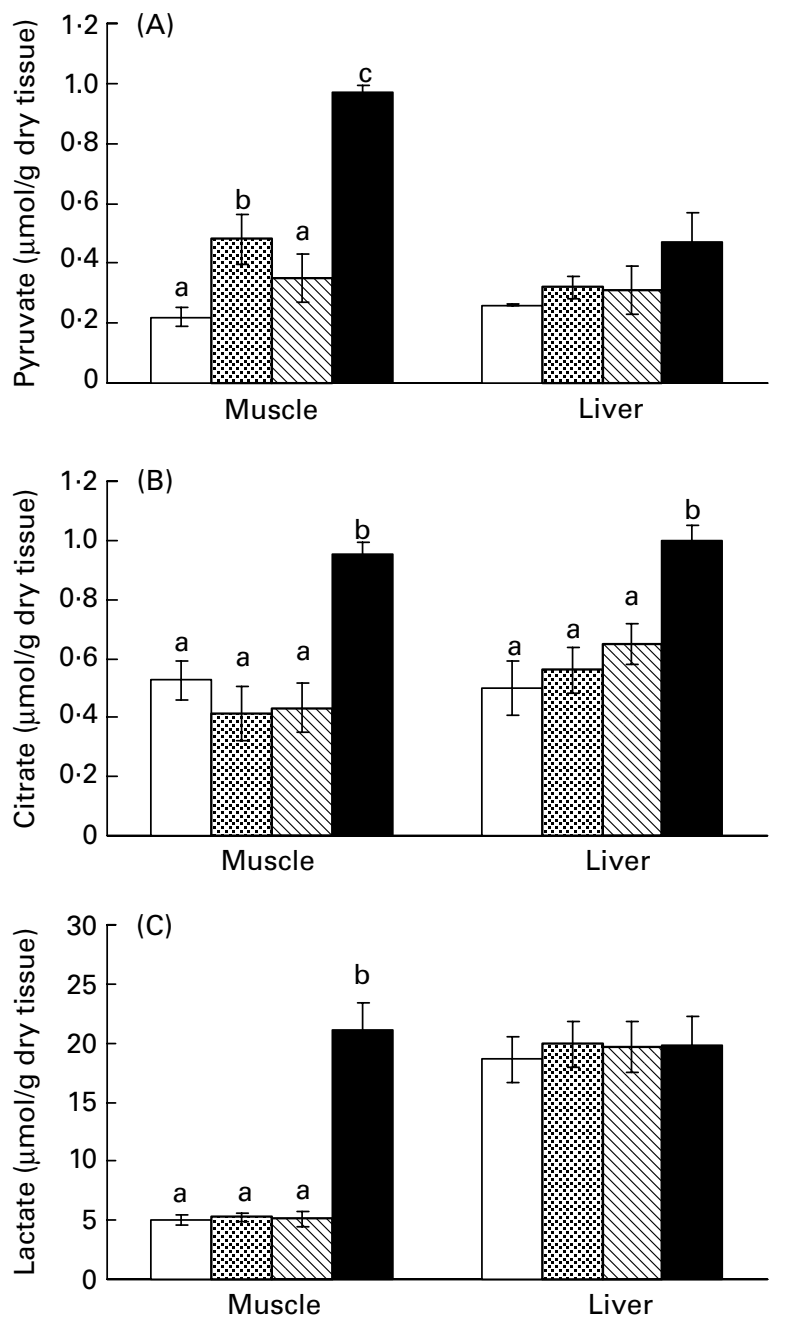

Fig. 3. Pyruvate $(A)$, citrate $(B)$ and lactate $(C)$ content in muscle and liver of animals fed high levels of fat. Values are means of five to six animals, with their standard errors represented by vertical bars. ( $\square$ ), Cis unsaturated fatty

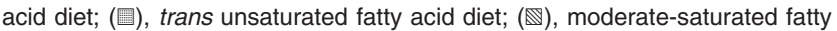
acid diet; $(\boldsymbol{\square})$, high-saturated fatty acid diet (see p. 949). ${ }^{a, b}$ Mean values with unlike letters were significantly different $(P<0.05)$ by Tukey's test, after significant differences were found by one-way ANOVA $(1 \times 4)$.

with significantly elevated plasma glucose levels, and with changes in muscle glucose metabolites. Thus, the high levels of muscle G-6-P, G-1-P, F-6-P, F-1,6-P , glyceraldehyde-3phosphate, lactate, pyruvate and citrate in rats fed a HSFA diet are associated with low muscle glucose and normal glycogen muscle stores, and reveal a glucose metabolic defect. Several mechanisms might partially explain the impairment of glucose metabolism. If the intracellular glucose-fatty acid cycle (Randle et al. 1963) is operating in gastrocnemius muscle, the high availability and oxidation of muscle triacylglycerol content in a HSFA diet could lead to increased levels of acetyl CoA. In turn, this could reduce the pyruvate dehydrogenase activity, and therefore increase the pyruvate and lactate levels in rats fed a HSFA diet. It has been shown that a high-fat diet significantly increases pyruvate dehydrogenase kinase-4 isoform expression, with a corresponding decrease in pyruvate dehydrogenase activity (Pehleman et al. 2005). The inhibition of pyruvate dehydrogenase activity could be at least partly responsible for the increases in intermediary glycolytic metabolites, including glycerol-3phosphate. Since glycerol-3-phosphate is a regulatory metabolite in triacylglycerol synthesis (Maggs et al. 1995), it is reasonable to suggest that raised levels of glycerol-3-phosphate could increase triacylglycerol synthesis, impairing the glucose metabolism. The higher availability and probably the oxidation of triacylglycerol in the muscle of HSFA-fed animals could also increase the muscle citrate levels, thereby reducing the PFK-1 and hexokinase activities. The very low F-1,6- $\mathrm{P}_{2}: \mathrm{F}-6-\mathrm{P}$ ratio in the HSFA diet indicates that flux through PFK-1 is reduced. The high citrate level and the acidic environment caused by lactate production might counteract the effect of PFK-1 activation by bisphosphorylated sugars (Andrés et al. 1990).

The elevated levels of plasma glucose, associated with low glucose concentration in gastrocnemius muscle, might suggest a deficiency in glucose transport in the muscle of rats fed a HSFA diet. These data are clearly consistent with a reduction of GLUT-4 gene expression in the muscle of animals fed $80 \%$ fat (\% energy) for 7 weeks described by Kahn \& Pedersen (1993). In addition, a HSFA diet might inhibit the GLUT by increasing muscle diacylglycerol concentrations (Montell et al. 2001). Thus, in the presence of increased levels of fatty acids, a high concentration of diacylglycerol activates a protein kinase (protein kinase $\mathrm{C}-\theta$ ), causing the serine phosphorylation of insulin receptor substrate-1 (Yu et al. 2002). Serine phosphorylated insulin receptor substrate-1 cannot recruit phosphatidyl-inositol-3-kinase and thus inhibits GLUT-4 translocation.

The huge accumulation of muscle lactate does not exclude the possibility that both an overproduction of lactate and a decrease in trans-sarcolemmal lactate transport could be present, as was described in experimental diabetes induced by
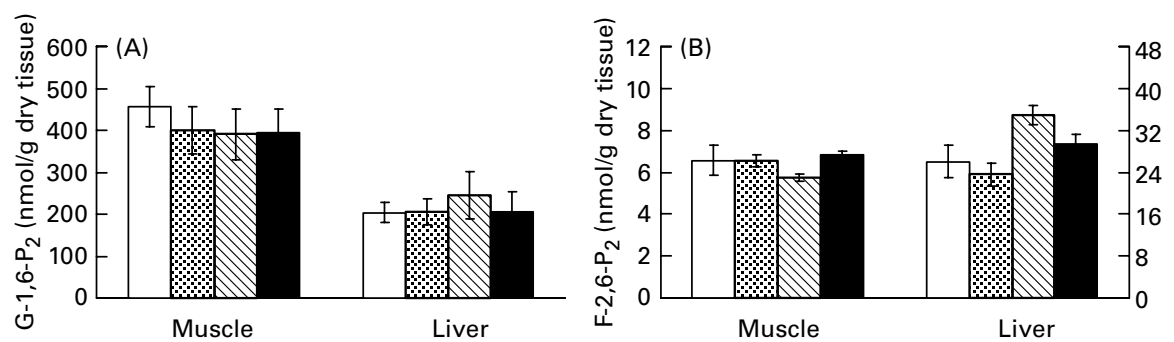

Fig. 4. Glucose-1,6-bisphosphate $\left(\mathrm{G}-1,6-\mathrm{P}_{2}\right)(\mathrm{B})$ and fructose-2,6-bisphosphate $\left(\mathrm{F}-2,6-\mathrm{P}_{2}\right)(\mathrm{B})$ content in the muscle and liver of animals fed high levels of fat. Values are means of five to six animals, with their standard errors represented by vertical bars. ( $\square$ ), Cis unsaturated fatty acid diet; (四), trans unsaturated fatty acid diet; $(\mathbb{Q})$, moderate-saturated fatty acid diet; $(\square)$, high-saturated fatty acid diet (see p. 949$)$. ${ }^{a, b}$ Mean values with unlike letters were significantly different $(P<0.05)$ by Tukey's test, after significant differences were found by one-way ANOVA $(1 \times 4)$. 

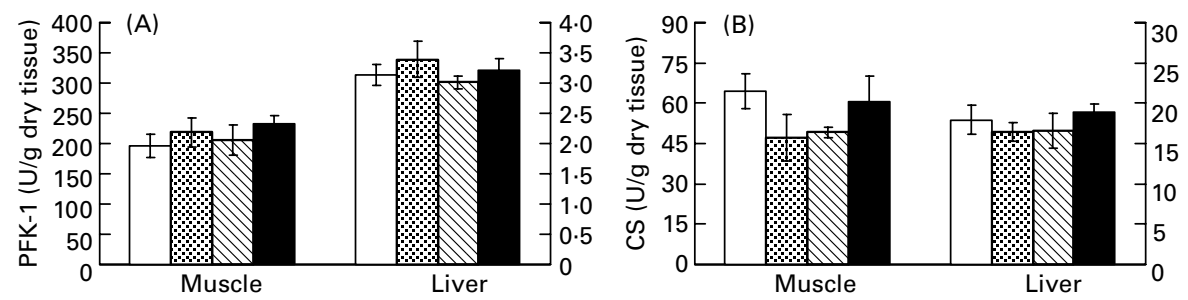

Fig. 5. 6-Phosphofructo-1-kinase (PFK-1) (A) and citrate synthase (CS) (B) activities in the muscle and liver of animals fed high levels of fat. Values are means of five to six animals, with their standard errors represented by vertical bars. ( $\square$ ), Cis unsaturated fatty acid diet; (回), trans unsaturated fatty acid diet; ( $\mathbb{Q}$ ), moderatesaturated fatty acid diet; $(\square)$, high-saturated fatty acid diet (see p. 949). ${ }^{\text {a,b }}$ Mean values with unlike letters were significantly different $(P<0.05)$ by Tukey's test, after significant differences were found by one-way ANOVA $(1 \times 4)$.

streptozotocin (Py et al. 2001). Moreover, Storlien et al. (1996) described changes in the fatty acid composition of membrane phospholipids induced by a HSFA diet. These alterations could affect membrane fluidity or permeability, supporting the plausible theory that there is a decrease in glucose and/or lactate transport.

In agreement with data recently reported by our group (Colandré et al. 2003), HSFA increased liver triacylglycerol content. However, this significant shift did not impact on the hepatic glucose metabolism to the same extent as observed in muscle. The significant increase in hepatic citrate levels with a HSFA diet seems to have a negligible impact on the glycolytic pathway after $30 \mathrm{~d}$ of feeding. It is not known whether feeding a HSFA diet for longer periods would lead to other hepatic metabolic disorders.

To our knowledge, the present study is the first to report the effect of dietary $t$ FA at high fat levels on glucose metabolites in the muscle and liver of experimental animals. A noteworthy aspect of the present study is the very little impact of the muscle glucose metabolites to high fat levels enriched with $t \mathrm{FA}$ as compared with HSFA. Thus, by reinforcing the key role of the high muscle lipids availability and oxidation as a driving force to the muscle glucose metabolism alterations in a HSFA diet, we found that rats fed high levels of $t \mathrm{FA}$ resulted in normal gastrocnemius muscle triacylglycerol content and thereby in a lack of glucose metabolite alterations in this muscle. In contrast, a $t$ FA (as HSFA) diet led to a significant accumulation of liver triacylglycerol content, without any significant changes in hepatic glucose metabolism. Moreover, these experimental data may be consistent with previous results from Louheranta et al. (1999), in which a $t$ FA diet in young healthy women resulted in changes in the plasma lipid profile, with no changes in glucose and insulin metabolism. On the other hand, Alstrup et al. (1999) found that $t$ FA potentiate glucose-stimulated insulin secretion more than the corresponding cis isomers.

Finally, the high-fat-level MSFA diet had a lesser effect on muscle and liver glucose metabolism. This might indicate that a certain level of dietary SFA has to be reached to induce glucose metabolic changes. Alternatively, dietary $c$ FA might counteract the negative impact of SFA on glucose metabolism. If the latter is true, these results might provide some evidence of the advantageous effect of replacing SFA with $c$ FA.

In short, under our experimental conditions, dietary fats had greater detrimental effects on glucose metabolism in muscle than in liver. The type of dietary fatty acid rather than the level of dietary fat content had an impact on muscle glucose metabolism. Glycolytic changes induced by the HSFA diet in muscle were a multifaceted abnormality. Glucose and lactate transport and intracellular glucose metabolism could play a key role in the biochemical defects involved in the detrimental effect of an HSFA diet on glucose metabolism. Dietary $t$ FA had a slight effect on glucose metabolism compared with the HSFA diet.

\section{Acknowledgements}

We wish to thank Walter DaRú and Adolfo Larese for their technical assistance. We are also grateful to Dr Ricardo Grau and Dr Miguel A. Baltanás for their valuable collaboration and advice on the fat isomerisation and hydrogenation procedure. We are grateful to Mr Robin Rycroft for his editorial support. Finally, we are grateful for the financial support received from: the Universidad Nacional del Litoral - Cursos de Acción para la Investigación y Desarrollo (CAI + D 2000 no. 13-1-22); Secretaría de Ciencia y Técnica - UNL; the Consejo Nacional de Investigaciones Científicas y Tecnológicas (PIP no. 02 930, Resol. 127/04); the Ministerio Español de Ciencia y Tecnología - BFI2002-00218; the FISS of the Instituto Carlos III (Red de Centros RCMN-C03708); the Agencia Española de Cooperación Internacional.

\section{References}

Adamo KB \& Graham TE (1998) Comparison of traditional measurements with macroglycogen and proglycogen analysis of muscle glycogen. J Appl Physiol 84, 908-913.

Alsaif MA \& Duwaihy MMS (2004) Influence of dietary fat quantity and composition on glucose and insulin sensitivity in rats. Nutr Res 24, 417-425.

Alstrup KK, Gregersen S, Jensen HM, Thomsen JL \& Hermansen K (1999) Differential effects of cis and trans fatty acids on insulin release from isolated mouse islets. Metabolism 48, 22-29.

Andrés V, Carreras J \& Cussó R (1990) Regulation of muscle phosphofructokinase by physiological concentrations of bisphosphorylated hexoses: effect of alkalinization. Biochem Biophys Res Comm 172, 328-334.

Aro A, Jauhiainen M, Partanen R, Salminen I \& Mutanen M (1997) Stearic acid, trans fatty acids, and dairy fat: effects on serum and lipoprotein lipids, apolipoproteins, lipoprotein(a), and lipid transfer proteins in healthy subjects. Am J Clin Nutr 65, 1419-1426.

Ascherio A, Katan MB, Zock PL, Stampfer MJ \& Willet WC (1999) Trans fatty acids and coronary heart disease. N Engl J Med $\mathbf{3 4 0}$, 1994-1998.

Bass A, Brdiczk D, Eyer P, Hofer S \& Pette D (1969) Metabolic differentiation of distinct muscle types at the level of enzymatic organization. Eur J Biochem 10, 198-206. 
Cadefau J, Casademont J, Grau JM, Fernández J, Balaguer A, Vernet M, Cussó R \& Urbano-Márquez A (1990) Biochemical and histochemical adaptation to sprint training in young athletes. Acta Physiol Scand 140, 341-351.

Clevidence BA, Judd JT, Schaefer EJ, Jenner JL, Lichtenstein AH, Muesing RA, Wittes J \& Sunkin ME (1997) Plasma lipoprotein (a) levels in men and women consuming diets enriched in saturated, cis-, or trans-monounsaturated fatty acids. Arterioscler Thromb Vasc Biol 17, 1657-1661.

Colandré ME, Diez RS \& Bernal CA (2003) Metabolic effects of trans fatty acids on an experimental dietary model. Br J Nutr 89, 631-638.

Cromer KD, Jenkins TC \& Thies EJ (1995) Replacing cis octadecenoic acid with trans isomers in media containing rat adipocytes stimulates lipolysis and inhibits glucose utilization. J Nutr $\mathbf{1 2 5}$, 2394-2399.

Grundy SM, Abate N \& Chandalia M (2002) Diet composition and the metabolic syndrome: what is the optimal fat intake? Am J Med 113, S25-S29.

Institute of Laboratory Animal Resources, Commission on Life Sciences \& National Research Council (1996) Guide to the Care and Use of Experimental Animals of the Laboratory. Washington, DC: National Academy Press.

Judd JT, Clevidence BA, Muesing RA, Wittes J, Sunkin ME \& Podczasy JJ (1994) Dietary trans fatty acids: effects on plasma lipids and lipoproteins of healthy men and women. Am J Clin Nutr 59, $861-868$.

Kahn BB \& Pedersen O (1993) Suppression of GLUT 4 expression in skeletal muscle of rats that are obese from high fat feeding but not from high carbohydrate feeding or genetic obesity. Endocrinology 132, 13-22.

Kim JK, Wi JK \& Youn JH (1996) Metabolic impairment precedes insulin resistance in skeletal muscle during high-fat feeding in rats. Diabetes 45, 651-658.

Kim JY, Nolte LA, Hansen PA, Han D, Ferguson K, Thompson PA \& Holloszy JO (2000) High-fat diet-induced muscle insulin resistance: relationship to visceral fat mass. Am J Physiol 279, R2057-R2065.

Laurell S (1966) A method for routine determination of plasma triglycerides. Scand J Clin Lab Invest 18, 668-672.

Lichtenstein AH, Kennedy E, Barrier P, Danford D, Ernst ND, Grundy SM, Leveille GA, Van Horn L, Williams CL \& Booth SL (1998) Dietary fat consumption and health. Nutr Rev 56, S3-S28.

Lichtenstein AH \& Schwab US (2000) Relationship of dietary fat to glucose metabolism. Atherosclerosis 150, 227-243.

Louheranta AM, Turpeinen AK, Vidgren HM, Schwab US \& Uusitupa MIJ (1999) A high-trans fatty acid diet and insulin sensitivity in young healthy women. Metabolism 48, 870-875.

Lowry OH \& Passonneau JV (1972) A Flexible System of Enzymatic Analysis. New York: Academic.

Maggs DG, Jacob R, Rife F, Lange R, Leone P, During MJ, Tamborlane WV \& Sherwin RS (1995) Interstitial fluid concentrations of glycerol, glucose and amino acids in human quadriceps muscle and adipose tissue. Evidence for significant lipolysis in skeletal muscle. J Clin Invest 96, 370-377.

Mohan IK \& Das UN (2001) Prevention of chemically induced diabetes mellitus in experimental animals by polyunsaturated fatty acids. Nutrition 17, 126-151.

Montell E, Turini M, Marotta M, Roberts M, Noé V, Ciudad C, Macé K \& Gomez-Foix AM (2001) DAG accumulation from saturated fatty acids desensitizes insulin stimulation of glucose uptake in muscle cells. Am J Physiol 280, E229-E237.

Oakes ND, Cooney GJ, Camilleri S, Chisholm DJ \& Kraegen EW (1997) Mechanisms of liver and muscle insulin resistance induced by chronic high-fat feeding. Diabetes 46, 1768-1774.

Passonneau JV, Lowry OH, Schulz DW \& Brown JG (1969) Glucose 1,6 diphosphate formation by phosphoglucomutase in mammalian tissues. J Biol Chem 244, 902-909.

Pehleman TL, Peters SJ, Heigenhauser GJ \& Spiet LL (2005) Enzymatic regulation of glucose disposal in human skeletal muscle after a high-fat, low-carbohydrate diet. J Appl Physiol 98, 100-107.

Py G, Eydoux N, Perez-Martin A, Raynaud E, Brun JF, Préfaut C \& Mercier J (2001) Streptozotocin-induced diabetes decreases rat sarcolemmal lactate transport. Metabolism 50, 418-424.

Randle PJ, Garland PB, Hales CN \& Newsholme EA (1963) The glucose fatty acid cycle: its role in insulin sensitivity and the metabolic disturbances of diabetes mellitus. Lancet i, 785-794.

Riccardi G, Giacco R \& Rivellese AA (2004) Dietary fat, insulin sensitivity and the metabolic syndrome. Clin Nutr 23, 447-456.

Reeves PG, Nielsen FH \& Fahey GC (1993) AIN-93 purified diets for laboratory rodents: final report of the American Institute of Nutrition ad hoc writing committee on the reformulation of the AIN76A rodent diet. J Nutr 123, 1939-1951.

Sabina RL, Swain JL, Bradley WG \& Holnes CW (1984) Quantification of metabolites in human skeletal muscle during rest and exercise. A comparison of methods. Muscle Nerve 7, 77-82.

Storlien LH, James DE, Burleigh KM, Chisholm DJ \& Kraegen EW (1986) Fat feeding causes widespread in vivo insulin resistance, decreased energy expenditure, and obesity in the rat. Am J Physiol 251, E576-E583.

Storlien LH, Jenkins AB, Chisholm DJ, Pascoe WS, Khouri S \& Kraegen EW (1991) Influence of dietary fat composition on development of insulin resistance in rats. Relationship to muscle triglyceride and $\omega-3$ fatty acids in muscle phospholipid. Diabetes 40 , 280-289.

Storlien LH, Kriketos AD, Jenkins AB, Baur LA, Pan DA, Tapsell LC \& Calvert GD (1997) Does dietary fat influence insulin action? Ann N Y Acad Sci 827, 287-301.

Storlien LH, Pan DA, Kriketos AD, O'Connor J, Caterson ID, Cooney GJ, Jenkins AB \& Baur LA (1996) Skeletal muscle membrane lipids and insulin resistance. Lipids 31, S261-S265.

Taouis M, Dagou C, Ster C, Durand G, Pinault M \& Delarue J (2002) n-3 Polyunsaturated fatty acids prevent the defect of insulin receptor signalling in muscle. Am J Physiol 282, E664-E671.

Uusitupa M, Schwab U, Mäkimattila S, Karhapää P, Sarkkinen E, Maliranta H, Agren J \& Penttilä I (1994) Effects of two high-fat diets with different fatty acid compositions on glucose and lipid metabolism in healthy young women. Am J Clin Nutr 59, 1310-1316.

van Schaftingen E, Lederer E, Bartrons R \& Hers HG (1982) A kinetic study of pyrophosphate: fructose-6-phosphate phosphotransferase from potato tubers. Eur J Biochem 129, 191-195.

Wang Y, Miura Y, Kaneko T, Li J, Qin LQ, Wang PY, Matsui H \& Sato A (2002) Glucose intolerance induced by a high-fat/lowcarbohydrate diet in rats. Effects of nonesterified fatty acids. Endocrine 17, 185-191.

Yu C, Chen Y \& Cline GW (2002) Mechanism by which fatty acids inhibit insulin activation of insulin receptor substrate-1 (IRS-1)associated phosphatidylinositol 3-kinase activity in muscle. $J$ Biol Chem 277, 50230-50236.

Zock PL \& Katan MB (1997) Trans fatty acids, lipoproteins, and coronary risk. Can J Physiol Pharmacol 75, 211-216. 